\title{
Genetic sensitivity to emotional cues, racial discrimination and depressive symptoms among African-American adolescent females
}

OPEN ACCESS

Edited by:

Gian Mauro Manzoni eCampus University, Italy

Reviewed by:

Lorena M. Estrada-Martinez, University of Massachusetts Boston, University, Italy Chiara Rollero,

eCampus University, Italy

*Correspondence. Jessica M. Sales Department of Behavioral Sciences and Health Education, Rollins School of Public Health, Emory University, 1518 Clifton Road, NE Room 570

Atlanta, GA 30322, USA jmcderm@emory.edu

Specialty section

This article was submitted to Psychology for Clinical Settings, a section of the journal Frontiers in Psychology

Received: 02 March 2015 Accepted: 09 June 2015 Published: 22 June 2015

Citation:

Sales JM, Brown JL Swartzendruber AL, Smearman EL, Brody GH and DiClemente R (2015) Genetic sensitivity to emotional cues, racial discrimination and depressive symptoms among African-American adolescent females.

Front. Psychol. 6:854 doi: 10.3389/fpsyg.2015.00854

\section{Jessica M. Sales ${ }^{1 *}$, Jennifer L. Brown ${ }^{2}$, Andrea L. Swartzendruber ${ }^{1}$ Erica L. Smearman ${ }^{1}$, Gene H. Brody ${ }^{1}$ and Ralph DiClemente ${ }^{1}$}

${ }^{1}$ Department of Behavioral Sciences and Health Education, Rollins School of Public Health, Emory University, Atlanta, GA, USA, ${ }^{2}$ Department of Psychological Sciences, Texas Tech University, Lubbock, TX, USA

Psychosocial stress, including stress resulting from racial discrimination (RD), has been associated with elevated depressive symptoms. However, individuals vary in their reactivity to stress, with some variability resulting from genetic differences. Specifically, genetic variation within the linked promoter region of the serotonin transporter gene (5-HTTLPR) is related to heightened reactivity to emotional environmental cues. Likewise, variations within this region may interact with stressful life events (e.g., discrimination) to influence depressive symptoms, but this has not been empirically examined in prior studies. The objective of this study was to examine whether variation in the 5-HTTLPR gene interacts with RD to predict depressive symptoms among a sample of African-American adolescent females. Participants were 304 AfricanAmerican adolescent females enrolled in a sexually transmitted disease prevention trial. Participants completed a baseline survey assessing psychosocial factors including RD (low vs. high) and depressive symptomatology (low vs. high) and provided a saliva sample for genotyping the risk polymorphism 5-HTTLPR (s allele present vs. not present). In a logistic regression model adjusting for psychosocial correlates of depressive symptoms, an interaction between RD and 5-HTTLPR group was significantly associated with depressive symptomatology $(\mathrm{AOR}=3.79,95 \% \mathrm{Cl}$ : $1.20-11.98, p=0.02$ ). Follow-up tests found that high RD was significantly associated with greater odds of high depressive symptoms only for participants with the $s$ allele. $\mathrm{RD}$ and 5-HTTLPR status interact to differentially impact depressive symptoms among African-American adolescent females. Efforts to decrease depression among minority youth should include interventions which address RD and strengthen factors (e.g., coping, emotion regulation, building support systems) which protect youth from the psychological costs of discrimination. 


\section{Introduction}

Across a wide range of health indicators, including mental health outcomes, dramatic racial and socioeconomic health disparities exist for African-American adolescents in the United States (Williams et al., 2010). A variety of factors have been examined to elucidate what drives these persistent disparities. A burgeoning body of literature indicates that racial discrimination (RD) may be a key factor associated with increased risk for many negative health outcomes, including both poorer physical (e.g., coronary artery calcification, sexually transmitted infections, and low birth-weight infants) and mental health outcomes (e.g., increased rates of internalizing and externalizing conditions; Lewis et al., 2006; Brondolo et al., 2008; Dominquez et al., 2008; Pascoe and Smart Richman, 2009; Williams and Mohammed, 2009; Rosenthal et al., 2014). Young African-American women in particular also experience high rates of depressive symptoms relative to their non-minority peers (Khan et al., 2009). For example, $19.3 \%$ of African-American adolescent women in the National Longitudinal Study of Adolescent Health endorsed recent and chronic depressive symptoms relative to $13.0 \%$ of White adolescent women (Khan et al., 2009). However, not everyone experiencing elevated stressors, including RD stress, evidences negative mental health outcomes. Thus, the primary purpose of this study was to examine the extent to which genetic variation moderates the association between $\mathrm{RD}$ and high levels of depressive symptomatology among a sample of adolescent African-American women. In other words, are some adolescent African-American women more affected than others by RD thereby resulting in higher levels of depressive symptoms?

Racial discrimination is defined as dominant group members' actions that have a differential and negative effect on subordinate racial/ethnic groups (Williams et al., 2003). Previous research has indicated that $91 \%$ of pre-adolescent African-Americans reported one or more experiences of race-related discrimination in their lifetime (Gibbons et al., 2004). Similarly, another study found that $77 \%$ of African-American youth reported experiencing one or more discriminatory events in the prior 3 months (Prelow et al., 2004). Specific to African-American female adolescents, Guthrie et al. (2002) found that $52 \%$ reported at least one exposure to $\mathrm{RD}$ in the past year (Guthrie et al., 2002). The Integrative Model for the Study of Developmental Competencies in Minority Children (Integrative Model) by Garcia Coll et al. (1996) proposes that individuals in American society are stratified based upon social position factors (e.g., race, social class, and gender), and social positions are influenced by $\mathrm{RD}$. Because $\mathrm{RD}$ is embedded within American society it is a normative and chronic exposure for African-American children and adolescents (Garcia Coll et al., 1996). Thus, RD is a pervasive challenge in the lives of adolescent African-American females, and has been posited by Thoits (1991) and more recently, by Jones (2000) to be a stressor that, if internalized (i.e., internalized racism), threatens the central parts of an individual's identity, thereby adversely affecting one's mental health.

A growing body of research suggests that $\mathrm{RD}$ is especially harmful to the mental health of African-American youth. Several cross-sectional studies have demonstrated that experiences with $\mathrm{RD}$ are associated with lower self-esteem, increased anger, and increased anxiety and depressive symptoms among AfricanAmerican adolescents (Prelow et al., 2004; Seaton et al., 2008; Gaylord-Harden and Cunningham, 2009). Many of these associations have been found in longitudinal studies as well. Specifically, racial discriminatory experiences are related to decreased self-esteem and increased conduct problems and depressive symptoms among African-American youth (Brody et al., 2006, 2011; Greene et al., 2006; Gibbons et al., 2007; Neblett et al., 2008; Estrada-Marinez et al., 2012).

Depression is one of the most common psychiatric issues affecting adolescents. At any given time, $\sim 15 \%$ of children and adolescents exhibit some symptoms of depression, while 5\% of 9- to 17-year-olds meet the criteria for a major depressive disorder (Birmaher et al., 1996; Shaffer et al., 1996). Specific to adolescents, the incidence of depressive disorders markedly increases after puberty. Moreover, by 14 years of age, depressive disorders are more than twice as common in females as in males (Angoid et al., 1999). Female adolescents, a group disproportionately affected by depression, experience heightened interpersonal, relationship stress relative to their male peers (Rudolph, 2002; Hampel and Petermann, 2006; Teva et al., 2010). Added to this, African-American adolescents encounter greater chronic, contextual or environmental stressors relative to their non-minority peers (Copeland-Linder et al., 2011) such as RD (Clark et al., 1999; Sellers et al., 2006; GaylordHarden and Cunningham, 2009), among others. Thus for African-American young women in particular, elevated exposure to chronic psychosocial and environmental stressors such as interpersonal stress and $\mathrm{RD}$ have been posited as core constructs that may underlie increased vulnerability to depressive disorders and heightened depressive symptoms (Estrada-Marinez et al., 2012). Despite this well-documented association between RD and increased depressive symptoms, surprisingly few studies have examined factors which moderate the association between $\mathrm{RD}$ and depressive symptomotology among African-American adolescent females (Seaton et al., 2014), and few, to our knowledge, have taken into account other common sources of stress also associated with depressive symptoms among young women (e.g., interpersonal stress and abuse history; EstradaMarinez et al., 2012).

Neuroscientists have noted that some individuals are particularly reactive to emotional environmental stimuli, such as exposure to racial discriminatory events. Functional magnetic resonance imaging (fMRI) studies suggest the amygdala, a region of the brain critical for emotional processing and especially important for detection and processing of anxiety and fear-related information, is affected by genetic variability in the promoter of the 5-HTT gene (5-HTTLPR; Nordquist and Oreland, 2010). The 5-HTT gene is a key regulator of serotonergic neurotransmission, localized to $17 \mathrm{p} 13$ and consisting of 14 exons and a single promoter. The common polymorphism in the promoter region results in two variants, a short and a long allele, with the short allele resulting in lower serotonin transporter availability. Although there has been continued debate about the extent to which 5-HTTLPR moderates the association between 
stress and depression (see Risch et al., 2009 and Karg et al., 2011 for recent meta-analyses on the topic), relative to those without a short allele, individuals with at least one copy of the short $(s)$ allele of the 5-HTTLPR who have also experienced stressful life events have been suggested to have higher rates of depressive disorders or depressive symptoms.

Aside from this conceptualization of the role of 5-HTTLPR in emotion-related processing, other studies have found that individuals with at least one copy of the $s$ allele of the 5HTTLPR have increased amygdala activation to fearful stimuli in facial expression recognition tasks and enhanced amygdala reactivity to punishment cues in the environment (Hariri et al., 2002, 2003; Battaglia et al., 2005; Hariri et al., 2006). Further, carriers of at least one copy of the $s$ allele also display hyperactive amygdala response to non-emotional and neutral cues (Heinz et al., 2007; Munafo et al., 2008), direct preferential attention toward threat-related stimuli, and also have difficulty disengaging from such stimuli (Osinsky et al., 2008; Beevers et al., 2009).

Taken together, neuroscience research suggests that carrying the $s$ allele may prompt enhanced emotional arousal to threatening and stressful environmental events, resulting in higher levels of depressive symptoms among those with high levels of stress exposure, particularly chronic environmental stressors (e.g., RD). In other words, these findings suggest that African-American adolescent females who experience high levels of RD AND who are also predisposed toward heightened emotional reactivity to environmental events by having at least one copy of the $s$ allele of the 5-HTTLPR should evidence greater levels of depressive symptoms than those without the genetic sensitivity or with lower levels of exposure to RD.

The purpose of the present study was to examine whether variation in the 5-HTTLPR gene interacts with level of RD to predict depressive symptoms among a sample of adolescent African-American females, while accounting for relevant factors such as coping and social support and stressors (abuse history and interpersonal stress). We hypothesized a gene by environment $(G \times E)$ interaction effect in which the association between high levels of RD and high levels of depressive symptoms would be more evident among those individuals carrying at least one copy of the $s$ allele of the 5-HTTLPR polymorphism.

\section{Materials and Methods}

\section{Description of Parent Study Recruitment}

This study is a secondary analysis of data collected as part of a randomized STD/HIV prevention trial specially designed and tailored for adolescent African-American female youth (HORIZONS; DiClemente et al., 2014). From July 2005 to June 2007 African-American adolescent females were recruited from three reproductive health clinics (an adolescent reproductive health clinic in a public hospital, a community located reproductive health clinic, and a county health department STD clinic in Atlanta, GA) to participate in an STD/HIV prevention trial. The adolescent clinic serves $\sim 2000$ clients annually, the majority of clients attending the clinic are ages 16-17, over
$90 \%$ of clinic attendees are sexually active and the vast majority (over 85\%) is African-American. The community-located clinic serves $\sim 3,300$ clients per year; around $80 \%$ of female clients are 14-29 years, and $\sim 50 \%$ are African-American. The county health department sexually transmitted disease (STD) clinic serves predominately African-American clients (over 80\%), with $\sim 5,000$ adolescent visits to their STD/HIV/AIDS Program annually. The median age of the teens attending the clinic for STD/HIV-related care was about 16 years, and females outnumber males by about two to one.

The purpose of the trial was to assess whether a supplemental treatment delivered after intervention workshop participation (via phone calls) enhanced maintenance of a modified efficacious STD/HIV behavioral intervention (HORIZONS; DiClemente et al., 2014). A young African-American woman recruiter approached adolescents in the clinic waiting area, described the study, solicited participation, and assessed eligibility. Eligibility criteria included self-identifying as African-American, being 14-20 years of age, and reporting at least one instance in the past 6 months of vaginal intercourse without a condom. Young women were excluded from the study if they were married, pregnant, or attempting to become pregnant. Those meeting inclusion criteria and interested in participating returned to the clinic to complete informed consent procedures, baseline assessments, and randomization to trial conditions. Written informed consent was obtained from all young women. Parental consent was waived for those younger than 18 due to the confidential nature of clinic services. Of the eligible individuals, 94\% $(N=701)$ enrolled in the study, completed baseline assessments and were randomized to study conditions. Participants were compensated $\$ 75$ for the baseline visit. The Emory University Institutional Review Board approved all study protocols.

\section{Procedures and Measures Relevant for the Current Study}

As part of the parent study's procedures, participants completed an audio computer assisted self-interviews (ACASI) at baseline, prior to randomization and intervention participation. The baseline ACASI data allowed for assessment of all variables included in this study such as sociodemographics, coping, social support, abuse history, interpersonal stress, $\mathrm{RD}$, and depressive symptoms. In addition to the baseline ACASI survey completed as part of the parent study, this analysis reports on data from the 304 participants who also consented and provided a saliva sample for DNA analysis ${ }^{1}$.

\section{Primary Outcome Variable Depressive symptoms}

Depressive symptoms were assessed with a very brief, eight-item version of the Center for Epidemiological Studies-Depression scale (Melchior et al., 1993). The CES-D assesses the presence of

${ }^{1}$ The DNA sample collection was an addition to the main trail's data collection. Because of this, not every participant was invited to provide a sample if they: (1) had already completed the trial, or (2) did not return for the 24 month followup assessment when the sample collection occurred. 363 were asked to provide a sample, and only 31 declined. 
depressive symptoms in the past 7 days and has been shown to be a valid measure of depressive symptoms in African-Americans (Radloff, 1991). A total score was first calculated with higher scores indicative of higher depressive symptom levels; the range of possible scores is $8-32$. Scores above 15 suggest clinically elevated depressive symptom levels (coded as 1 ) relative to those with scores below 15 (coded as 0 ). Cronbach's $\alpha$, a measure of the scale's internal consistency, was 0.91 .

\section{Primary Predicator Variable Racial discrimination}

A 13-item revised version of the Schedule for Racist Events scale (SRE; Landrine and Klonoff, 1996) was used to measure RD. This revised version has been extensively used by other researchers among adolescent and young adult samples (Simons et al., 2003, 2006; Gibbons et al., 2004; Brody et al., 2006). The revised SRE assessed the frequency during the past year, ranging from 1 (never) to 4 (several times), with which the participant experienced specific discriminatory behaviors such as racially based slurs or insults, disrespectful treatment from community members, physical threats, and false accusations from law officials or business employees. The mean score ( mean $=20.36, \mathrm{SD}=6.93$; median $=20$; possible range $=13-52$; observed range $=13-45$ ) was used to split the sample into those reporting higher than the average levels of discrimination experiences (scores greater than $20=1$ "high discrimination") and those reporting average or lower discrimination experiences (scores 20 or less $=0$ "low discrimination"). Cronbach's $\alpha$ was 0.90 .

\section{Control Variables \\ Sociodemographic measures}

Age was assessed by asking, "How old are you (in years)?" Also, clinic location was included as a control variable as participants were recruited from three downtown Atlanta reproductive health/STD clinics; each serving slightly different populations in regards to SES and education.

\section{Psychosocial Correlates Interpersonal stress}

A 13-item modified version of the African-American Women's Stress Scale (Watts-Jones, 1990) was used to measure interpersonal or family stressors. Questions assess the amount of stress an individual feels in various interpersonal relationships or contexts (e.g., relationships with family, partner not being faithful, and isolation from family). Cronbach's $\alpha$ for the scale was 0.87 .

\section{History of abuse}

Abuse was conceptualized as an index comprising four forms of abuse; emotional, physical, forced vaginal sex or forced anal sex. Abuse history was assessed by asking four questions, "Have you ever been emotionally abused (threatened or called names)," Have you ever been physically abused (hit, kicked, slapped, punched)?", "Has anyone ever forced you to have vaginal sex when you didn't want to?", and "Has anyone ever forced you to have anal sex when you didn't want to?”. Response choices were yes (1) and no
(0). Consistent with the definition used in national surveillance studies (Leeb et al., 2008), a dichotomous composite variable was created in which participants who indicated yes on any of the four items were determined to have a history of abuse, and those who answered no on all items were determined to have no history of abuse.

\section{Coping}

A 14-item modified version of the COPE scale was used to assess reliance on avoidance-based coping (Carver et al., 1989). Examples of coping behaviors queried were, "I act as though it hasn't even happened," or "I admit to myself that I can't deal with it, and quit trying." Higher scores indicate more reliance on avoidance-based coping. Cronbach's $\alpha$ was 0.78 .

\section{Social support}

Social support was assessed with a 12 -item scale (Zimet et al., 1988). Responses were coded so that higher scores reflected higher levels of perceived social support by the adolescent. An example item is, "I get the emotional help and support I need from my family." Cronbach's $\alpha$ was 0.90 .

\section{Genotyping}

DNA was obtained using Oragene ${ }^{\mathrm{TM}}$ DNA kits (Genetek; Calgary, AB, Canada). Participants rinsed their mouths with tap water, and then deposited $4 \mathrm{ml}$ of saliva in the Oragene sample vial. The vial was sealed, inverted, and shipped via courier to a central laboratory in Iowa City, where samples were prepared according to the manufacturer's specifications. Genotype at 5-HTTLPR was determined for each sample as previously described (Bradley et al., 2005). Of the sample, $9.2 \%$ were homozygous for the short allele (ss), $34.2 \%$ were heterozygous $(s l)$, and $56.6 \%$ were homozygous for the long allele (ll). Consistent with prior research (Hariri et al., 2005), genotyping results were used to form two groups of participants: those homozygous for the long allele $(n=172)$ and those with either 1 or 2 copies of the short allele $(n=132)$. Among the 332 participants who provided a saliva sample, $5.12 \%(n=17)$ had a "very long" variant of 5-HTTLPR. Because the activity of this variant on the hypothesized associations has not been well characterized, these youths were excluded from the data analyses.

\section{Data Analysis Plan}

All analyses were limited to the 304 main trial participants who, in addition to the baseline assessment, consented and provided a valid saliva sample for DNA analysis. Descriptive statistics summarized study variables. In addition, bivariate analyses examined associations between control variables, 5$H T T L P R$ group (i.e., $s$ allele group vs. $l l$ allele group), psychosocial factors associated with managing stressful experiences (i.e., social support and coping), RD group (i.e., low vs. high) and depressive symptoms (i.e., low vs. high). Associations were assessed using Pearson's correlations and Chi-square analyses. Variables significant at the $p \leq 0.10$ in bivariate analyses were entered into a multivariable hierarchical logistic regression predicting high depressive symptoms (Hosmer and Lemeshow, 2000), controlling for age and clinic. In the first step, psychosocial correlates were entered into the model. In the second step, RD 
and 5-HTTLPR were entered into the model. In the final step, to explore whether the association between discrimination and depressive symptoms differed as a function of 5-HTTLPR group, an interaction between discrimination group and 5-HTTLPR group was entered in at this step of the regression model.

\section{Results}

\section{Sample Description}

Descriptive statistics for all measures are presented in Table $\mathbf{1}$. The majority was still in high-school or had only completed some high-school at enrollment (53.9\%). Many reported living with their mother only (42.9\%), and approximately a quarter had a job for which they were paid. Many of the participants were recruited from a county health department STD clinic $(n=154)$, others were recruited from a reproductive health clinic $(n=119)$, and the remaining participants were recruited from an adolescent reproductive health clinic in a public hospital $(n=31)$. Of the 304 participants in this study $82.2 \%(n=250)$ endorsed experiencing a least one of the 13 forms of $\mathrm{RD}$ on in the past year.

\section{Bivariate Associations Among Study Variables}

Pearson correlations or Chi-square tests were conducted among potential control variables, the primary predictor variable (RD), 5-HTTLPR status and depressive symptoms. Only significant ( $p \leq 0.05)$, or marginally significant $(p \leq 0.10)$, associations are described. Specific to the control variables, participant age was positively correlated with $\mathrm{RD}(r=0.15, p=0.01)$. Also, participants recruited from the health department STD clinic were more likely to report high depressive symptoms (40.9\%) than those recruited from the adolescent clinic $(32.3 \%)$, and the reproductive health clinic $(27.7 \%) ; \chi^{2}=5.24, p=0.07$. Among the psychosocial factors, interpersonal stress $(r=0.40$, $p<0.001)$, history of abuse $(r=0.32, p<0.001)$, and avoidance-based coping $(r=0.27, p<0.001)$ were each positively correlated with higher depressive symptoms. Participants with high RD were more likely (45.7\%) to report high depressive symptoms compared to the those with low discrimination

TABLE 1 | Descriptive statistics of the study sample on study variables $(N=304)$.

\begin{tabular}{lll}
\hline & Mean & SD \\
\hline Sociodemographic & 18.09 & 1.40 \\
Age & & \\
Possible psychosocial control variables & 28.41 & 13.51 \\
Interpersonal stress & 18.94 & 4.64 \\
Coping & 35.99 & 5.80 \\
Social support & 197 & 64.8 \\
Abuse history (frequency/\%) & Frequency & $\%$ \\
\hline Primary predictor variable & 127 & 41.8 \\
\hline High racial discrimination & & \\
Outcome & & 34.9 \\
High depressive symptoms $^{\mathrm{a}}$ & 106 & \\
\hline a & &
\end{tabular}

a Rather than means and SD, frequency and percent is displayed.
$(29.4 \%) ; \chi^{2}=19.63, p<0.001$. However, participants 5-HTTLPR status was not significantly related to depressive symptoms $(r=0.03, p=0.67)$, nor were participants with an $s$ allele more likely to report higher $\mathrm{RD}(43.2 \%)$ than those in the $l l$ allele group $(40.7 \%) ; \chi^{2}=0.19, p=0.66$.

\section{Multivariable Hierarchical Logistic Regression Predicting Level of Depression Symptoms}

Overall, we found that the three step model including the interaction term was significant (see Table 2). The interaction between RD and 5-HTTLPR group was significantly associated with the probability of being in the high depressive symptom group above and beyond the psychosocial factors. In order to interpret the interaction effect, separate multivariable logistic regression models for level of depressive symptoms were conducted for those possessing one or two copies of the $s$ allele and those with the $l l$ allele (see Table 3). For both those with the $s$ and the $l l$ genotypes, having higher interpersonal stress and a history or abuse were associated with higher odds for elevated depressive symptoms. However, RD was associated with higher odds of elevated depressive symptoms only among those with the $s$ allele, but engagement in avoidance-based coping was associated with higher odds for elevated depressive symptoms among the ll-genotype.

An additional follow-up test was conducted to further examine the proposed differential susceptibility hypothesis, whereby those with the $s$ allele are more sensitive toward and responsive to their environment. A layered Chi-Square test was conducted, with separate Chi-Square tests run by 5 -HTTLPR group ( $s$ allele group and the $l l$ allele group) to determine the association between level of RD (low vs. high) and level of depressive symptoms (low vs. high) for each genetic group (see Figure 1). For those youth in the s allele group $(n=132)$, participants with high levels of discrimination experiences were significantly more likely to report high levels of depressive symptoms $(45.6 \%)$ than those with low levels of discrimination experiences $(22.7 \%) ; \chi^{2}=7.77, p=0.005$. In contrast, among those in the $l l$ allele group $(n=172)$, participants with high levels of discrimination experiences were not more likely to report high levels of depressive symptoms (41.4\%) than those with low levels of discrimination experiences $(33.3 \%) ; \chi^{2}=1.17, p=0.28$.

\section{Discussion}

Similar to previous reports of RD levels in the U.S., almost all participants in this African-American adolescent female sample reported experiencing $\mathrm{RD}$ in the prior year, with $\sim 41 \%$ indicating higher than average experiences of discrimination. This sample also showed high levels of depressive symptoms, with $\sim 35 \%$ reporting levels of depressive symptoms that are potentially clinically significant. In addition to other stressors (interpersonal stress and abuse histories), as expected (Prelow et al., 2004; Seaton et al., 2008; Gaylord-Harden and Cunningham, 2009), RD was significantly associated with depressive symptoms among this all female sample. However, results demonstrated a moderating role of 5-HTTLPR genotype status in this outcome. Among this 
TABLE 2 | Multivariable hierarchical logistic regression predicting level of depressive symptoms.

\begin{tabular}{|c|c|c|c|c|c|c|}
\hline \multirow[b]{2}{*}{ Predictors } & \multirow[b]{2}{*}{$\beta$} & \multirow[b]{2}{*}{ SE } & \multirow[b]{2}{*}{ Odds ratio } & \multicolumn{2}{|c|}{$95 \% \mathrm{Cl}$} & \multirow[b]{2}{*}{$p$} \\
\hline & & & & Lower & Upper & \\
\hline \multicolumn{7}{|l|}{ Step 1} \\
\hline \multicolumn{7}{|l|}{ Psychosocial correlates } \\
\hline Interpersonal stress & 0.06 & 0.01 & 1.06 & 1.04 & 1.08 & 0.001 \\
\hline Coping & 0.11 & 0.03 & 1.12 & 1.05 & 1.20 & 0.001 \\
\hline Abuse history & 1.15 & 0.36 & 3.15 & 1.56 & 6.35 & 0.001 \\
\hline \multicolumn{7}{|l|}{ Step 2} \\
\hline 5-HTTLPR group & -0.72 & 0.40 & 0.49 & 0.22 & 1.06 & 0.071 \\
\hline Racial discrimination group & -0.28 & 0.39 & 0.76 & 0.35 & 1.66 & 0.486 \\
\hline \multicolumn{7}{|l|}{ Step 3} \\
\hline Discrimination $\times$ 5-HTTLPR group & 1.33 & 0.58 & 3.79 & 1.20 & 11.98 & 0.023 \\
\hline Step $1 x^{2}=$ & 82.15 & & & & & 0.001 \\
\hline Step $2 \chi^{2}=$ & 1.16 & & & & & 0.561 \\
\hline Step $3 x^{2}=$ & 5.31 & & & & & 0.021 \\
\hline Overall model $\chi^{2}=$ & 88.61 & & & & & 0.001 \\
\hline
\end{tabular}

Age and clinic were controlled for in regression.

TABLE 3 | Multivariable logistic regressions predicting level of depressive symptoms, separately for each 5-HTTLPR group.

\begin{tabular}{|c|c|c|c|c|c|c|}
\hline \multirow[b]{2}{*}{ Predictors } & \multirow[b]{2}{*}{$\beta$} & \multirow[b]{2}{*}{ SE } & \multirow[b]{2}{*}{ Odds ratio } & \multicolumn{2}{|c|}{$95 \% \mathrm{Cl}$} & \multirow[b]{2}{*}{$p$} \\
\hline & & & & Lower & Upper & \\
\hline \multicolumn{7}{|l|}{ 5-HTTLPR s allele group } \\
\hline \multicolumn{7}{|l|}{ Primary predictor } \\
\hline Racial discrimination group & 0.91 & 0.45 & 2.48 & 1.02 & 6.05 & 0.045 \\
\hline \multicolumn{7}{|l|}{ Psychosocial factors } \\
\hline Interpersonal stress & 0.06 & 0.02 & 1.06 & 1.02 & 1.10 & 0.002 \\
\hline Coping & 0.05 & 0.05 & 1.05 & 0.95 & 1.16 & 0.358 \\
\hline Abuse history & 1.38 & 0.55 & 3.93 & 1.33 & 11.64 & 0.014 \\
\hline Overall $\chi^{2}=$ & 36.05 & & & & & 0.001 \\
\hline \multicolumn{7}{|l|}{ 5-HTTLPR /I allele group } \\
\hline \multicolumn{7}{|l|}{ Primary predictor } \\
\hline Racial discrimination group & -0.20 & 0.43 & 0.82 & 0.35 & 1.90 & 0.637 \\
\hline \multicolumn{7}{|l|}{ Psychosocial factors } \\
\hline Interpersonal stress & 0.06 & 0.02 & 1.06 & 1.03 & 1.09 & 0.001 \\
\hline Coping & 0.16 & 0.05 & 1.18 & 1.08 & 1.29 & 0.001 \\
\hline Abuse history & 0.96 & 0.49 & 2.61 & 1.01 & 6.76 & 0.048 \\
\hline Overall $\chi^{2}=$ & 55.55 & & & & & 0.001 \\
\hline
\end{tabular}

Age and clinic were controlled for in regressions.

sample of young African-American women, high exposure to RD was associated with greater odds of elevated depressive symptoms only for young women with the $s$ allele, even when accounting for multiple sources of stress and psychosocial factors, while the link between $\mathrm{RD}$ and depressive symptoms was attenuated for those with the $l l$ genotype. Among individuals with this genotype, greater reliance on avoidance-based coping behaviors were instead significantly associated with likelihood of elevated depression symptoms.

Adolescence is a period of great developmental change (Crosby et al., 2009) characterized by increasing levels of psychosocial stressors (Compas, 1987). For young women especially, adolescence is a time when many may experience depressive symptoms for the first time (Angoid et al., 1999). African-American adolescents may also encounter additional chronic, contextual or environmental stressors relative to their non-minority peers (Copeland-Linder et al., 2011; EstradaMarinez et al., 2012). This stressful exposure includes RD, which has been specifically associated with increased risk for elevated depressive symptoms particularly among young women (Clark et al., 1999; Sellers et al., 2006; Gaylord-Harden and Cunningham, 2009). The genetic marker of 5-HHTLPR as indicated through the neuroscience findings seems to be especially relevant for the detection of fear or threat specific 


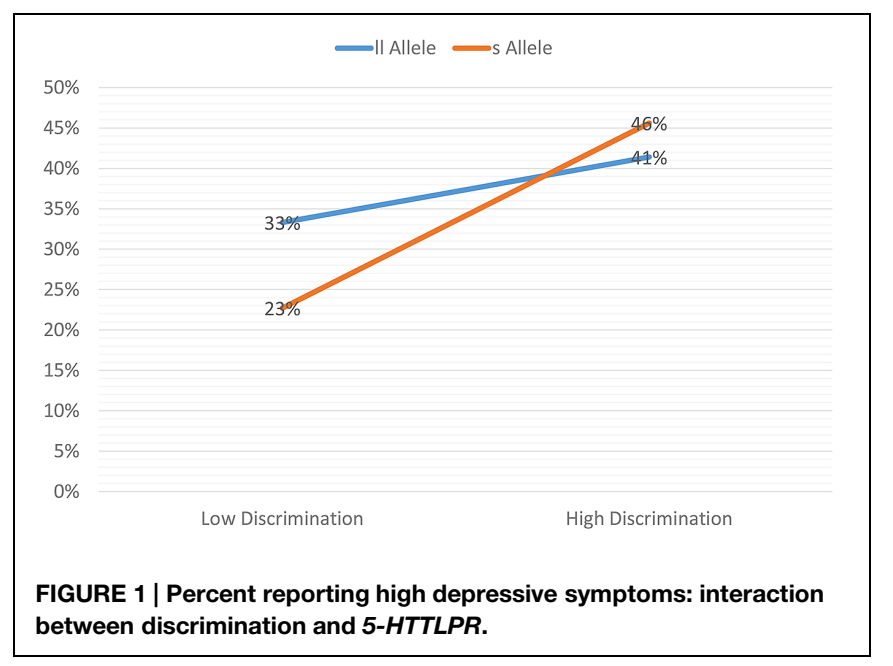

stimuli in the environment (particularly in facial cues). The neuroscience findings that individuals with the $s$ allele seem to be hyperaroused and hypersensitive to cues of fear/threat make this marker particularly important in the context of some stressors (like racial discriminatory behaviors such as physical threats, slurs, insults, and it is also relevant for individuals with histories of physical or sexual abuse as well), but it may not be as relevant in other stressful contexts that may not contain the same sort of emotional triggers detected by monitoring others emotional states, such as interpersonal stressors like someone owing you money, or minor daily hassles captured in our interpersonal stress scale. However, this speculation warrants further examination.

In accordance with the differential susceptibility theories (Belsky et al., 2007), we found a link between exposure to high levels of RD and depressive symptoms among youth who carried the one of two copies of the $s$ allele of the 5-HTTLPR. This finding is consistent with neuroimaging studies and prior $\mathrm{G} \times \mathrm{E}$ research involving the 5-HTTLPR such that female youth who carry the short allele, because of their genetic makeup, may be more reactive to emotional or threating social cues in their environments (e.g., being disrespectfully treated by community members) and are therefore more negatively impacted by experiences of RD than those with the $l l$ genotype. The finding that carrying two copies of the long allele may confer protection from depressive symptoms when they experience high levels of discrimination is relevant to research on youth resilience.

The resilience literature has addressed potential reasons why some youth who experience adverse experiences, including exposures to chronic stressors, do not succumb to their negative effects (Luthar, 2006). The present results support recent findings suggesting that genetic status may also contribute to resilience (Rutter and Silberg, 2002; Moffitt et al., 2006; KimCohen and Gold, 2009; Brody et al., 2011). Particularly, the finding that carrying two $l$ alleles attenuates the association between discrimination and depressive symptoms suggests a possible emotional self-regulatory mechanism by which genotype contributes to the down regulation of emotions resulting from discriminatory experiences (Simons et al., 2003, 2006; Brody et al., 2011), but this potential mechanistic pathway requires further investigation. Further, the potentially protective effects of the $l l$ allele may not be generalizable to all youth, or under all contexts. Similar to Estrada-Marinez et al.'s (2012) findings that not all stressors are equally impactful on externalizing and internalizing outcomes, our results also suggest that young women with the $l l$ allele may be resilient in some areas but experience distress in others, such as when they experience certain aspects of interpersonal relationships that may not be perceived as threatening yet cause stress.

Our findings also are in line with Belsky et al. (2007) differential susceptibility hypothesis in which gene-specific variants are speculated to render individuals more susceptible to their surrounding environments, whether those be "good" or "bad" environments. Specifically, we observed that young women who carried the $s$ allele, in low discriminatory contexts reported lower levels of depressive symptoms than did $l l$ allele carriers (see Figure 1), thereby supporting the hypothesis of differential susceptibility. However, we know very little about other positive or protective attributes of these young women's environments, but this would be an important avenue for further investigation, especially as it may shed light on potential protective factors that could serve as intervention opportunities to decrease adverse mental health outcomes among those adolescent women exposed to high levels of discrimination.

From an intervention perspective, the results suggest that young African-American women seeking sexual health services would benefit from additional resources and skills training to address depressive symptoms and cope with chronic, pervasive stressors including experiences of RD. For example, multiple health-related intervention approaches may benefit from inclusion of content to improve coping and self-management strategies. Specifically, it may be especially beneficial given the high rates of stress (whether from interpersonal relationships or from experiences of discrimination) that health promotion programs for adolescent and young adult African-American females in general include mental-health specific components, such as teaching developmentally appropriate stress-coping skills and cognitive behavioral management skills (Antoni et al., 2001) mindfulness training that would help youth learn relaxation techniques for managing uncontrollable stressors (Bishop, 2002), and strategies for building and accessing social support systems. These components could be integrated into existing STD prevention interventions in the case of this study, or other health promotion programs, to address likely unmet mental health needs of the youth who are experiencing high levels of discrimination or other chronic stressors. Importantly, for some youth (those with the $s$ allele) who are particularly reactive to environmental cues of threat, other clinical techniques (e.g., exposure therapy approaches) may be useful to reduce threat sensitivity.

\section{Limitations}

This study is not without limitations. First, the sample consisted of adolescents who were seeking services at sexual health clinics, who met eligibility criteria for the parent study, and 
who attended the follow-up visit when the genetic sample was collected. Therefore results may not generalize to individuals who do not access similar clinics, who would not meet the eligibility criteria, which included having recent unprotected sex, or who are not likely to return for follow-up. Future research should include a broader sample of youth, as well as include males to extend or replicate these findings. Also, the data employed in this study were only from participants who returned at the 24-month follow-up assessment and provided a saliva sample. It is possible that returning participants may have differed in meaningful ways from those who did not return for follow-up, but we have no way to formally examine this possibility. However, analyses of baseline socioeconomic indicate no significant differences between those who returned for follow-up and those who did not. Additionally, participants who provided DNA samples may have differed from participants who did not provide a specimen. However, we experienced a high rate of participation for the DNA saliva collection (92\%), and a comparison of baseline characteristics indicates no observed differences in sociodemographics, psychosocial variables, or behavioral outcomes. Finally, the self-report data are cross-sectional, making it difficult to assess causal relationships, although a strength is that we directly assessed RD in our study.

\section{Conclusion}

Adolescence is a period of life characterized by developmental change and increasing levels of psychosocial stressors (Compas, 1987). For African-Americans, many will encounter additional chronic, contextual or environmental stressors such as exposure to $\mathrm{RD}$ relative to their non-minority peers (CopelandLinder et al., 2011; Estrada-Marinez et al., 2012). However, consistent with neuroimaging studies and prior $\mathrm{G} \times \mathrm{E}$

\section{References}

Angoid, A., Costello, E. J., Erkanli, A., and Worthman, C. M. (1999). Pubertal changes in hormone levels and depression in girls. Psychol. Med. 29, 1043-1053. doi: 10.1017/S0033291799008946

Antoni, M. H., Lehman, J. M., Klibourn, K. M., Boyers, A. E., Culver, J. L., Alferi, S. M., et al. (2001). Cognitive-behavioral stress management intervention decreases the prevalence of depression and enhances benefit finding among women under treatment for early-stage breast cancer. Health Psychol. 20, 20-32. doi: 10.1037/0278-6133.20.1.20

Battaglia, M., Ogliari, A., Zanoni, A., Citterio, A., Pozzoli, U., Giorda, R., et al. (2005). Influence of the serotonin transporter promoter gene and shyness on children's cerebral responses to facial expressions. Arch. Gen. Psychiatry 62, 85-94. doi: 10.1001/archpsyc.62.1.85

Beevers, C. G., Wells, T. T., Ellis, A. J., and McGeary, J. E. (2009). Association of the serotonin transporter gene promoter region (5-HTTLPR) polymorphism with biased attention for emotional stimuli. J. Abnorm. Psychol. 118, 670-681. doi: $10.1037 / \mathrm{a} 0016198$

Belsky, J., Bakermans-Kranenburg, M. J., and van Ijzendoorn, M. H. (2007). For better and for worse: differential susceptibility to environmental influence. Curr. Dir. Psychol. Sci. 16, 300-304. doi: 10.1111/j.1467-8721.2007. 00525.x

Birmaher, B., Ryan, N. D., Williamson, D. E., Brent, D. A., and Kaufman, J. (1996). Childhood and adolescent depression: a review of the past 10 years. Part II. research involving the 5-HTTLPR, for some individuals, because of their genetic make-up, they are particularly susceptible to negative psychological consequences resulting from high exposure to $\mathrm{RD}$ than others. Given the high rates of depressive symptoms coupled with high number of stressors reported among adolescent African-American (whether from abuse experiences, interpersonal relationships or from experiences of discrimination) it may be advantageous for health promotion programs targeting adolescent and young adult African-American females in general to include mentalhealth specific components, such as teaching developmentally appropriate stress management and cognitive behavioral skills.

\section{Acknowledgments}

We would like to express our gratitude to the many staff that contributed their time and energy to this project. We would like to particularly thank the young women who gave of their time to participate in the project. This research was supported by a grant, number K01 MH085506, from the National Institute of Mental Health to the first author, a Medical Scientist Training grant, number T32 GM008169 provided support for ES. JB was supported by National Institute on Drug Abuse grant number R03DA0377860. AS was supported by National Institute on Alcohol Abuse and Alcoholism grant number F32AA022058. Also, grant number R01 MH070537, from the National Institute of Mental Health to RD, and number P30DA02782 to GB provided support for the research. Additional research support was provided through the Emory Center for AIDS Research (P30 AI050409). The content is solely the responsibility of the authors and does not necessarily represent the official views of the National Institute of Mental Health, the National Institute on Drug Abuse, or National Institute of Health.

J. Am. Acad. Child Adolesc. Psychiatry 35, 1575-1583. doi: 10.1097/00004583199612000-00008

Bishop, S. R. (2002). What do we really know about mindfulness-based stress reduction? Psychosom. Med. 64, 71-83. doi: 10.1097/00006842-20020100000010

Bradley, S. L., Dodelzon, K., Sandhu, H. K., and Philibert, R. A. (2005). Relationship of serotonin transporter gene polymorphisms and haplotypes to mRNA transcription. Am. J. Med. Genet. Behav. Neuropsychiat. Genet. 136B, 58-61. doi: 10.1002/ajmg.b.30185

Brody, G. H., Beach, S. R. H., Chen, Y., Obasi, E., Philibert, R. A., Kogan, S. M., et al. (2011). Perceived discrimination, serotonin transporter linked polymorphic region status, and the development of conduct problesm. Dev. Psychopathol. 23, 617-627. doi: 10.1017/S0954579411000046

Brody, G. H., Chen, Y., Murray, V. M., Ge, X., Simons, R. L., Gibbons, F. X., et al. (2006). Perceived discrimination and the adjustment of African American youth: a five-year longitudinal analysis with contextual moderation effects. Child Dev. 77, 1170-1189. doi: 10.1111/j.1467-8624.2006.00927.x

Brondolo, E., Brady, N., Thompson, S., Tobin, J., Cassells, A., Sweeney, M., et al. (2008). Perceived racism and negative affect: analysis of trait and state measures of affect in a community sample. J. Soc. Clin. Psychol. 27, 150-173. doi: $10.1521 /$ jscp.2008.27.2.150

Carver, C. S., Scheier, M. F., and Weintraub, J. K. (1989). Assessing coping strategies: a theoretically based approach. J. Pers. Soc. Psychol. 56, 267-283. doi: 10.1037/0022-3514.56.2.267 
Clark, R., Anderson, N. B., Clark, V. R., and Williams, D. R. (1999). Racism as a stressor for African Americans: a biopsychosocial model. Am. Psychol. 54, 805-816. doi: 10.1037/0003-066X.54.10.805

Compas, B. E. (1987). Stress and life events during childhood and adolescence. Clin. Psychol. Rev 7, 275-302. doi: 10.1016/0272-7358(87)90037-7

Copeland-Linder, N., Lambert, S. F., Chen, Y.-F., and Ialongo, N. S. (2011). Contextual stress and health risk behaviors among African American adolescents. J. Youth and Adolesc. 40, 158-173. doi: 10.1007/s10964-010-9520-y

Crosby, R. A., Santelli, J. S., and DiClemente, R. J. (2009). “Adolescents at risk: a generation in jeopardy," in Adolescent Health: Understanding and Preventing Risk Behaviors, eds R. DiClemente, J. Santelli, and R. Crosby (San Francisco, CA: Jossey-Bass), 3-6.

DiClemente, R. J., Wingood, G. M., Sales, J. M., Brown, J. L., Rose, E. S., Davis, T. L., et al. (2014). Efficacy of a telephone-delivered sexually transmitted infection/human immunodeficiency virus prevention maintenance intervention for adolescents: randomized clinical trial. JAMA Pediatr. 168, 938-946. doi: 10.1001/jamapediatrics.2014.1436

Dominquez, T. P., Dunkel-Schetter, C., Glynn, L. M., Hobel, C., and Sandman, C. A. (2008). Racial differences in birth outcomes: the role of general, pregnancy, and racism stress. Health Psychol. 27, 194-203. doi: 10.1037/02786133.27.2.194

Estrada-Marinez, L. M., Caldwell, C. H., Bauermeister, J. A., and Zimmerman, M. A. (2012). Stessors in multiple life-domains and the risk for externalizing and internalizing behaviors among African Americans during emerging adulthood. J. Youth Adolesc. 41, 1600-1612. doi: 10.1007/s10964-012-9778-3

Garcia Coll, C., Lamberty, G., Jenkins, R., McAdoo, H. P., Crnic, K., Wasik, B. H., et al. (1996). An integrative model for the study of developmental competencies in minority children. Child Dev. 67, 1891-1914. doi: 10.2307/ 1131600

Gaylord-Harden, N. K., and Cunningham, J. A. (2009). The impact of racial discrimination and coping strategies on internalizing symptoms in African American youth. J. Youth and Adolesc. 38, 532-543. doi: 10.1007/s10964-0089377-5

Gibbons, F. X., Gerrard, M., Cleveland, M. J., Wills, T. A., and Brody, G. H. (2004). Perceived discrimination and substance use in African American parents and their children: a panel study. J. Pers. Soc. Psychol. 86, 517-529. doi: 10.1037/0022-3514.86.4.517

Gibbons, F. X., Yeh, H. C., Gerrard, M., Cleveland, M. J., Cutrona, C., Simons, R. L., et al. (2007). Early experiences with racial discrimination and conduct disorder as predictors of subsequent drug use: a critical period hypothesis. Drug Alcohol Depend. 88, 27-37. doi: 10.1016/j.drugalcdep.2006.12.015

Greene, M. L., Way, N., and Pahl, K. (2006). Trajectories of perceived adult and peer discrimination among Black, Latino, and Asian American adolescents: patterns and psychological correlates. Dev. Psychol. 42, 218-238. doi: 10.1037/00121649.42.2.218

Guthrie, B. J., Young, A. M., Williams, D. R., Boyd, C. J., and Kintner, E. K. (2002). African-American girls' smoking habits and day-to-day smoking experiences with racial discrimination. Nurs. Res. 51, 183-190. doi: 10.1097/00006199200205000-00007

Hampel, P., and Petermann, F. (2006). Perceived stress, coping, and adjustment in adolescents. J. Adolesc. Health, 38, 409-415. doi: 10.1016/j.jadohealth. 2005.02.014

Hariri, A. R., Drabant, E. M., Munoz, K. E., Kolechana, B. S., Mattay, V. S., Egan, M. F., et al. (2005). A susceptibility gene for affective disorders and the response of the human amygdala. Arch. Gen. Psychiatry 62, 146-152. doi: 10.1001/archpsyc.62.2.146

Hariri, A. R., Drabant, E. M., and Weinberger, D. R. (2006). Imaging genetics: perspectives from studies of genetically driven variation in serotonin function and corticolimbic affective processing. Biol. Psychiatry 59, 888-897. doi: 10.1016/j.biopsych.2005.11.005

Hariri, A. R., Mattay, V. S., Tessitore, A., Fera, F., and Weinberger, D. R. (2003). Neocortical modulation of the amygdala response to fearful stimuli. Biol. Psychiatry 53, 494-501. doi: 10.1016/S0006-3223(02)01786-9

Hariri, A. R., Mattay, V. S., Tessitore, A., Kolachana, B., Fere, F., Goldman, D., et al. (2002). Serotonin transporter genetic variation and the response of the human amygdala. Science 297, 400-403. doi: 10.1126/science.1071829

Heinz, A., Smolka, M. N., Braus, D. F., Wrase, J., Beck, A., Flor, H., et al. (2007). Serotonin transporter genotype (5-HTTLPR): effects of neutral and undefined conditions on amygdala activation. Biol. Psychiatry 61, 1011-1014. doi: 10.1016/j.biopsych.2006.08.019

Hosmer, D. W., and Lemeshow, S. L. (2000). Applied Logistic Regression. New York: Wiley. doi: 10.1002/0471722146

Jones, C. P. (2000). Levels of racism: a theoretical framework and a Gardener's tale. Am. J. Public Health 90, 1212-1215. doi: 10.2105/AJPH.90.8.1212

Karg, K., Burmeister, M., Shedden, K., and Sen, S. (2011). The serotonin transporter promoter variant (5-HHTLPR), stress, and depression Meta-analysis revisited. Arch. Gen. Psychiatry 68, 444-454. doi: 10.1001/archgenpsychiatry.2010.189

Khan, M. R., Kaufman, J. S., Pence, B. W., Gaynes, B. N., Adimora, A. A., Weir, S. S., et al. (2009). Depression, sexually transmitted infection, and sexual risk behavior among young adults in the United States. Arch. Pediatr. Adolesc. Med. 163, 644-652. doi: 10.1001/archpediatrics.2009.95

Kim-Cohen, J., and Gold, A. L. (2009). Measured gene-environment interactions and mechanisms promoting resilient development. Curr. Dir. Psychol. Sci. 18, 138-142. doi: 10.1111/j.1467-8721.2009.01624.x

Landrine, H., and Klonoff, E. A. (1996). The Schedule of Racist Events: a measure of racial discrimination and a study of its negative physical and mental health consequences. J. Black Psychol. 22, 144-168. doi: 10.1177/00957984960222002

Leeb, R. T., Paulozzi, L. J., Melanson, C., Simon, T. R., and Arias, I. (2008). Child Maltreatment Surveillance: Uniform Definitions for Public Health and Recommended Data Elements, Version 1.0 (Atlanta, GA: Centers for Disease Control and Prevention, National Center for Injury Prevention and Control). Available at: http://www.cdc.gov/violenceprevention/ pdf/CM_Surveillance-a.pdf

Lewis, T., Everson-Rose, S., Powell, L. H., Matthews, K. A., Brown, C., Karavolos, K., et al. (2006). Chronic exposure to everyday discrimination and cononary artery calcification in African-American women: the SWAN Heart Study. Psychosom. Med. 68, 362-368. doi: 10.1097/01.psy.0000221360. 94700.16

Luthar, S. S. (2006). "Resilience in development: a synthesis of research across five decades," in Developmental Psychopathology: Vol. 3. Risk, Disorder, and Adaptation, 2nd Edn, eds D. Cicchetti and D. J. Cohen (Hoboken, NJ: Wiley), 739-795.

Melchior, L. A., Huba, G. J., Brown, V. B., and Reback, C. J. (1993). A short depression index for women. Educ. Psychol. Meas. 53, 1117-1125. doi: 10.1177/0013164493053004024

Moffitt, T. E., Caspi, A., and Rutter, M. L. (2006). Measured gene-environment interactions in psychopathology: concepts, research strategies, and implications for research, intervention, and public understanding of genetics. Perspect. Psychol. Sci. 1, 5-27. doi: 10.1111/j.1745-6916.2006.00002.x

Munafo, M. R., Brown, S. M., and Hariri, A. R. (2008). Serotonin transporter (5-HTTLPR) genotype and amygdala activation: a meta-analysis. Biol. Psychiatry 63, 852-857. doi: 10.1016/j.biopsych.2007.08.016

Neblett, E. W., White, R. L., Ford, K. R., Philip, C. L., Nguyen, H. X., and Sellers, R. M. (2008). Patterns of racial socialization and psychological adjustment: can parental communications about race reduce the impact of racial discrimination? J. Res. Adolesc. 18, 477-515. doi: 10.1111/j.15327795.2008.00568.x

Nordquist, N., and Oreland, L. (2010). Serotonin, genetic variability, behaviour, and psychiatric disorders - a review. UPS J. Med. Sci. 115, 2-10. doi: 10.3109/03009730903573246

Osinsky, R., Reuter, M., Kupper, Y., Schmitz, A., Kozyra, E., Alexander, N., et al. (2008). Variation in the serotonin transporter gene modulates selective attention to threat. Emotion 8, 584-588. doi: 10.1037/a0012826

Pascoe, E. A., and Smart Richman, L. (2009). Perceived discrimination and health: a meta-analytic review. Psychol. Bull. 135, 531-554. doi: 10.1037/a0016059

Prelow, H. M., Danoff-Burg, S., Swenson, R. R., and Pulgiano, D. (2004). The impact of ecological risk and perceived discrimination on the psychological adjustment of African-American and European American youth. J. Commun. Psychol. 32, 375-389. doi: 10.1002/jcop.20007

Radloff, L. S. (1991). The use of the Center for Epidemiologic Studies Depression Scale in adolescents and young adults. J. Youth Adolesc. 20, 149-166. doi: 10.1007/BF01537606

Risch, N., Herrell, R., Lehner, T., Liang, K., Eaves, L., Hoh, J., et al. (2009). Interaction between the serotonin transporter gene (5-HTTLRP), stressful life events, and risk of depression. JAMA 301, 2462-2471. doi: $10.1001 /$ jama.2009.878 
Rosenthal, L., Earnshaw, V. A., Lewis, J. B., Lewis, T. T., Reid, A. E., Stasko, E. C., et al. (2014). Discrimination and sexual risk among young urban pregnant women of color. Health Psychol. 33, 3-10. doi: 10.1037/a0032502

Rudolph, K. D. (2002). Gender differences in emotional responses to interpersonal stress during adolescence. J. Adolesc. Health, 30(Suppl. 4), 3-13. doi: 10.1016/S1054-139X(01)00383-4

Rutter, M. J., and Silberg, J. (2002). Gene-environment interplay in relation to emotional and behavioral disturbance. Annu. Rev. Psychol. 53, 463-490. doi: 10.1146/annurev.psych.53.100901.135223

Seaton, E. K., Caldwell, C. H., Sellers, R. M., and Jackson, J. S. (2008). The prevalence of perceived discrimination among African American and Caribbean Black youth. Dev. Psychol. 44, 1288-1297. doi: 10.1037/a0012747

Seaton, E. K., Upton, R., Gilbert, A., and Volpe, V. (2014). A moderated mediation model: racial discrimination, coping strategies, and racial idenity among black adolescents. Child Dev. 85, 882-890. doi: 10.1111/cdev.12122

Sellers, R. M., Copeland-Linder, N., Martin, P. P., and Lewis, R. L. H. (2006). Racial identity matters: the relationship between racial discrimination and psychological functioning in African American adolescents. J. Res. Adolesc. 16, 187-216. doi: 10.1111/j.1532-7795.2006.00128.x

Shaffer, D., Gould, M. S., Fisher, P., Trautman, P., Moreau, D., Kleinman, M., et al. (1996). Psychiatric diagnosis in child and adolescent suicide. Arch. Gen. Psychiatry 53, 339-348. doi: 10.1001/archpsyc.1996.018300400 75012

Simons, R. L., Chen, Y., Stewart, E. A., and Brody, G. H. (2003). Incidents of discrimination and risk for delinquency: a longitudinal test of strain theory with an African-American sample. Justice Q. 20, 827-854. doi: $10.1080 / 07418820300095711$

Simons, R. L., Simons, L. G., Burt, C. H., Drummund, H., Stewart, E. A., Brody, G. H., et al. (2006). Supportive parenting moderates the effect of discrimination upon anger, hostile view of relationships, and violence among African American boys. J. Health Soc. Behav. 47, 373-389. doi: 10.1177/00221465060 4700405
Teva, I., Bermúdez, M. P., and Buela-Casal, G. (2010). Sexual sensation seeking, social stress, and coping styles as predictors of HIV/STD risk behaviors in adolescents. Youth Soc. 42, 255-277. doi: 10.1177/0044118X09353572

Thoits, P. A. (1991). On merging identity theory and stress research. Soc. Psychol. Q. 54, 101-112. doi: $10.2307 / 2786929$

Watts-Jones, D. (1990). Toward a stress scale for African-American women. Psychol. Women Q. 14, 271-275. doi: 10.1111/j.1471-6402.1990.tb00019.x

Williams, D. R., and Mohammed, S. A. (2009). Discrimination and racial disparities in health: evidence and needed research. J. Behav. Med. 32, 20-47. doi: 10.1007/s10865-008-9185-0

Williams, D. R., Mohammed, S. A., Leavell, J., and Collins, C. (2010). Race, socioeconomic status, and health: complexities, ongoing challenges, and research opportunities. Ann. N. Y. Acad. Sci. 1186, 69-101. doi: 10.1111/j.17496632.2009.05339.x

Williams, D. R., Neighbors, H. W., and Jackson, J. S. (2003). Racial/ethnic discrimination and health: findings from community studies. Am. J. Public Health 93, 200-208. doi: 10.2105/AJPH.93.2.200

Zimet, G., Dahlem, N., Zimet, S., and Farley G. (1988). The multidimensional scale of perceived social support. J. Pers. Assess. 52, 30-41. doi: 10.1207/s15327752jpa5201_2

Conflict of Interest Statement: The authors declare that the research was conducted in the absence of any commercial or financial relationships that could be construed as a potential conflict of interest.

Copyright (ㅇ 2015 Sales, Brown, Swartzendruber, Smearman, Brody and DiClemente. This is an open-access article distributed under the terms of the Creative Commons Attribution License (CC BY). The use, distribution or reproduction in other forums is permitted, provided the original author(s) or licensor are credited and that the original publication in this journal is cited, in accordance with accepted academic practice. No use, distribution or reproduction is permitted which does not comply with these terms. 